\title{
Catheter Ablation for Atrial Fibrillation in Patients with Hemophilia or von Willebrand Disease
}

\author{
Paul R. van der Valk ${ }^{1} \quad$ Eveline P. Mauser-Bunschoten ${ }^{1} \quad$ Jeroen F. van der Heijden ${ }^{2} \quad$ Roger E. G. Schutgens ${ }^{1}$ \\ 1 Van Creveldkliniek, University Medical Center, University Utrecht, \\ Utrecht, The Netherlands \\ 2 Division Heart and Lung, Cardiology, Electrophysiology, UMC \\ Utrecht, Utrecht, The Netherlands

\begin{abstract}
Address for correspondence Paul R. van der Valk, MD, University Medical Center Utrecht, Van Creveldkliniek, Heidelberglaan 100, PO Box 85060, 3508 AB Utrecht, The Netherlands (e-mail: p.r.vandervalk@umcutrecht.nl).
\end{abstract}

TH Open 2019;3:e335-e339.

\begin{abstract}
Background Management of atrial fibrillation (AF) is complex in patients with bleeding disorders. Catheter ablation such as pulmonary vein isolation (PVI) has been suggested in cases with bleeding disorders. However, data on safety are missing. This report describes the outcome of PVI in patients with bleeding disorders.

Methods A retrospective study in our hemophilia treatment center of patients who underwent a PVI in 2014 to 2018. PVI was done according to local protocol. Clotting factor was given periprocedural. Postprocedural anticoagulation was given for at least 4 weeks, with clotting factor suppletion if needed to maintain factor VIII (FVIII) levels $>0.20 \mathrm{IU} / \mathrm{mL}$.

Results and Discussion Five patients with hemophilia and one with von Willebrand disease were included. Eight PVIs were performed. Target FVIII levels (>0.80 IU/mL) were met before the procedure. Postprocedural anticoagulation was given: vitamin $\mathrm{K}$ antagonist (VKA) or direct oral anticoagulant (DOAC) dabigatran. All patients obtained long-term sinus rhythm, in two patients after a second PVI. However, late recurrent AF

\section{Keywords}

- atrial fibrillation

- Hemophilia A

- von Willebrand Disease

- catheter ablation

- anticoagulant

- bleeding occurred in one patient after 42 months. A notable incidence of groin bleeds was observed: two of eight interventions (25\%) compared with $0.9 \%$ in the general population. Bleeding seemed to be related to agitation, early mobilization, and bridging of VKA with low molecular weight heparin (LMWH). No relevant bleeding was observed when on DOAC therapy.

Conclusion PVI seems to be effective in the case of bleeding disorders. To reduce the groin bleeds agitation and early mobilization should be avoided and DOAC is preferred over bridging VKA with LMWH.
\end{abstract}

\section{Introduction}

Life expectancy in patients with hemophilia (PWHs) has increased significantly to almost normal. ${ }^{1}$ They are therefore more likely to be confronted with age-related comorbidity like cardiovascular disease (CVD). CVD mortality has been reported to be lower than the general population but numbers are increasing. ${ }^{2,3} \mathrm{~A}$ common CVD in the aging population is atrial fibrillation (AF). AF can cause ischemic stroke. The risk of

received

May 23, 2019

accepted after revision

September 5, 2019
DOI https://doi.org/

10.1055/s-0039-1698756. ISSN 2512-9465. an ischemic stroke in patients without bleeding disorders can be estimated with the so-called $\mathrm{CHA}_{2} \mathrm{DS}_{2}$-VASC score, ${ }^{4}$ but its applicability in hemophilia is questioned. ${ }^{5}$ Management of $\mathrm{PWH}$ and $\mathrm{AF}$ is complex in finding the balance between coagulation and anticoagulation. In a large cross-sectional study, the prevalence of AF in PWH was comparable with that of the general population; however, anticoagulation management was diverse. ${ }^{6}$ The most challenging patients are those with a high bleeding and stroke risk. In these
(C) 2019 Georg Thieme Verlag KG Stuttgart · New York
License terms

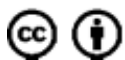


patients, we question if the use of catheter ablation (like pulmonary vein isolation [PVI]) is a feasible option to treat these patients. However, the feasibility of PVI in patients with bleeding is unknown. Here we describe our experience in patients with bleeding disorders undergoing PVI to treat their arrhythmia-related symptoms.

\section{Methods}

In this retrospective single-center cohort, we collected data from patients visiting the hemophilia treatment center (Van Creveldkliniek, University Medical Center Utrecht, The Netherlands) who underwent a PVI between 2014 and 2018. Data on baseline characteristics, type of bleeding disorder, comorbidity, reason for PVI, and procedural outcomes were extracted from the medical files. This project was approved by the local medical ethical committee.

\section{Pulmonary Vein Isolation}

Prior to PVI, evaluation of three-dimensional (3D) cardiac imaging was done by a cardiac computed tomography (CT) scan providing detailed left atrial anatomy and confirming the absence of a left atrium appendage thrombus.

Electrophysiological studies were performed in a sedated, fasting state. Catheters were introduced through the right femoral vein using three sheaths (once 7 French and twice 8.5 French). An octapolar catheter was positioned in the coronary sinus. The left atrium was reached by means of a transseptal puncture. A 3D cardiac mapping system (Carto; Biosense Webster, Diamond Bar, California, United States) was used to obtain a 3D reconstruction of the cardiac anatomy. An irrigated tip catheter (ThermoCool SmartTouch, Biosense Webster) was used to widely encircle the right and left pulmonary veins (PVs) at their antrum with pointby-point ablation lesions. Procedures were performed as described before. ${ }^{7}$ Endpoint of ablation procedure was electrical isolation of all PVs, as determined with the circular mapping catheter. PV isolation had to be consistent after a waiting period of 30 minutes after the last ablation application.

At the end of the procedure, sheaths were removed followed by manual compression of the femoral vein for at least 10 minutes. Thereafter compression dressing was placed for a least 4 hours and after its removal additional bedrest was continued for another 4 hours.

\section{Definition of Success}

There were two different definitions of success. During the "blanking period," the period after the procedure, reoccurrence of AF is normally not seen as failure.

Success rate of single PVI: no signs of AF following the 3month "blanking period" through the last follow-up. Overall success rate: no AF following one or more PVIs and a 3-month "blanking period" through the last follow-up. ${ }^{8}$

\section{Coagulation Management}

Patients with baseline FVIII $>0.20 \mathrm{IU} / \mathrm{mL}$ started at least 4 weeks prior to PVI with anticoagulation: vitamin Kantagonist
(VKA) or direct oral anticoagulant (DOAC) dabigatran $110 \mathrm{mg}$ twice daily.

Clotting factor correction aiming at a peak FVIII level of 0.8 to $1.0 \mathrm{IU} / \mathrm{mL}$ was started 1 hour before the procedure. Target trough levels were aimed at $0.5 \mathrm{IU} / \mathrm{mL}$ and peak levels were maintained at 0.8 to $1.0 \mathrm{IU} / \mathrm{mL}$ for the first 24 hours, for which two additional bolus injections were given with 12-hour interval.

Anticoagulation during the PVI procedure was according to the local standard protocol with unfractionated heparin (UFH) therapy with a target activated clotting time (ACT) of 300 to 350 seconds.

Before April 2016, 4 to 8 hours after the procedure therapeutic dosed low molecular weight heparin (LMWH: dalteparin, twice daily $100 \mathrm{IE} / \mathrm{kg}$ ) was started in combination with VKA. LMWH was stopped when a therapeutic international normalized ratio (INR) $>2.0$ was obtained. Duration of VKA therapy was dependent on the extent and result of PVI, with a minimum of 4 weeks. During VKA therapy FVIII trough levels were kept above $0.2 \mathrm{IU} / \mathrm{mL}$.

Since April 2016 dabigatran (110 mg twice-daily) was used instead of VKA therapy, avoiding the need for bridging with LMWH during PVI. In patients with FVIII $>0.2 \mathrm{IU} / \mathrm{mL}$, it was started 4 weeks before the procedure. In patients with FVIII $<0.2 \mathrm{IU} / \mathrm{mL}$, it was started 4 to 8 hours after the procedure. Postprocedural DOAC was continued for at least 4 weeks, in combination with FVIII suppletion with a target FVIII trough level above $0.2 \mathrm{IU} / \mathrm{mL}$.

\section{Results}

\section{Patients}

Five patients with hemophilia A and one with von Willebrand disease underwent a total of eight PVIs at a mean age of 62.2 years (-Table $\mathbf{1}$ ). Two patients had severe hemophilia and three mild. One patient had a history of a past inhibitor against FVIII, but currently has a normal FVIII half-life. Median duration of AF before the first PVI was 5 (interquartile range [IQR]: $4.75-7$ ) years. Median $\mathrm{CHA}_{2} \mathrm{DS}_{2}$-VASC score was 0.5 (IQR: 0-2.25). All patients were suffering from symptomatic AF. Median follow-up after the last PVI was 33 months (IQR: 10.25-43.75).

\section{Before PVI}

Two patients were on anticoagulation therapy before the PVI (-Table 2). Patient 1 (with a $\mathrm{CHA}_{2} \mathrm{DS}_{2}$-VASC 3 and FVIII 0.35 $\mathrm{IU} / \mathrm{mL}$ ) was on long-term VKA therapy before his first PVI and on long-term dabigatran before the second PVI. The other (patient 3) was on dabigatran before PVI for 4 weeks.

\section{During PVI}

According to the protocol, during all the procedures, boluses of UFH were administered, based on the ACT results, without any complications.

In all cases of hemophilia, target FVIII levels periprocedural were met. The mean dose of the first bolus was $31.7 \mathrm{IU} / \mathrm{kg}$ (IQR: 16.9-43.9) and the mean peak FVIII was $1.14 \mathrm{IU} / \mathrm{mL}$. The patient with von Willebrand disease reached a peak von 
Table 1 Patient characteristics

\begin{tabular}{|l|l|l|l|l|l|l|l|l|}
\hline Patient & Age & $\begin{array}{l}\text { Bleeding } \\
\text { disorder }\end{array}$ & $\begin{array}{l}\text { Clotting factor } \\
\text { level (IU/mL) }\end{array}$ & $\begin{array}{l}\text { Reason for } \\
\text { intervention }\end{array}$ & $\begin{array}{l}\mathrm{CHA}_{2} \mathrm{DS}_{2} \\
\text { VASC }\end{array}$ & $\begin{array}{l}\text { Duration } \\
\text { (y) }\end{array}$ & $\begin{array}{l}\text { Prior therapy } \\
\text { On chronic } \\
\text { anticoagulation } \\
\text { before PVI }\end{array}$ \\
\hline 1 & 70 & HA & FVIII 0.35 & $\begin{array}{l}\text { AF: dyspnea and } \\
\text { fatigue }\end{array}$ & 3 & 5 & CV, ECV & VKA \\
\hline 2 & 72 & HA & FVIII $<0.01$ & $\begin{array}{l}\text { pAF: with severe } \\
\text { fatigue }\end{array}$ & 1 & 7 & BB & No \\
\hline 3 & 59 & HA & FVIII 0.23 & $\begin{array}{l}\text { pAF: bradycardia } \\
\text { with decreased } \\
\text { ejection fraction }\end{array}$ & 0 & 4 & $\begin{array}{l}\text { ECV, } \\
\text { flecainide }\end{array}$ & No \\
\hline 4 & 50 & HA & FVIII $<0.01$ & $\begin{array}{l}\text { pAF: frequent } \\
\text { tachycardia }\end{array}$ & 0 & 5 & $\begin{array}{l}\text { CV, } \\
\text { flecainide, BB }\end{array}$ & No \\
\hline 5 & 55 & HA & FVIII 0.06 & $\begin{array}{l}\text { pAF: persistent } \\
\text { paroxysm under } \\
\text { medication }\end{array}$ & 0 & 5 & Flecainide, BB & No \\
\hline 6 & 67 & VWD & $\begin{array}{l}\text { vWF RCo 19\% } \\
\text { FVIII } 0.50\end{array}$ & $\begin{array}{l}\text { AF: dyspnea and } \\
\text { fatigue }\end{array}$ & 2 & 7 & $\begin{array}{l}\text { VATS Maze; } \\
\text { ECV }\end{array}$ & No \\
\hline
\end{tabular}

Abbreviations: AF, atrial fibrillation; BB, beta-blocker; CV, chemical cardioversion; ECV, electric cardioversion; $\mathrm{HA}$, hemophilia A; pAF, paroxysmal atrial fibrillation; RCo, ristocetin cofactor (IU/dL); VWD, von Willebrand disease; vWF, von Willebrand factor; VATS Maze: video assisted thoracoscopic surgery.

Table 2 Interventions-outcome and complications

\begin{tabular}{|c|c|c|c|c|c|c|c|}
\hline \multicolumn{2}{|c|}{ Intervention } & \multirow{2}{*}{$\begin{array}{l}\text { Patient } \\
1\end{array}$} & \multirow{2}{*}{$\begin{array}{l}\text { Outcome } \\
\text { SR, later } \\
\text { PAF }\end{array}$} & \multirow{2}{*}{$\begin{array}{l}\text { AC before } \\
\text { VKA }\end{array}$} & \multirow{2}{*}{$\begin{array}{l}\text { AC after procedure } \\
3 \text { mo VKA }\left(\text { LMWH }^{\mathrm{b}}\right)\end{array}$} & \multirow{2}{*}{$\begin{array}{l}\text { Stopped } \\
\text { VKA/DOAC } \\
\text { No: recurrent pAF }\end{array}$} & \multirow{2}{*}{$\begin{array}{l}\begin{array}{l}\text { Periprocedural } \\
\text { groin bleeding }\end{array} \\
\text { Day } 5: \mathrm{Hb} \text { drop } \\
3.22 \mathrm{~g} / \mathrm{dL}\end{array}$} \\
\hline 1 & $\mathrm{PVI}$ & & & & & & \\
\hline 2 & PVI (redo) & 1 & SR & Dabigatran $^{a}$ & Dabigatran $^{\mathrm{a}}$ & No & No \\
\hline 3 & PVI & 2 & $\begin{array}{l}\text { SR, later } \\
\text { pAF }\end{array}$ & No & 1 mo VKA (LMWH' & $\begin{array}{l}\text { Yes, as planned } \\
\text { after } 1 \mathrm{mo}\end{array}$ & $\begin{array}{l}\text { Day 3: Hb drop } \\
4.83 \mathrm{~g} / \mathrm{dL}\end{array}$ \\
\hline 4 & PVI (redo) & 2 & $\begin{array}{l}\text { SR under } \\
\text { sotalol }\end{array}$ & No & $\begin{array}{l}1 \text { mo VKA }\left(\text { LMWH }^{\mathrm{b}}\right) \text {, } \\
2 \text { mo ASA }\end{array}$ & $\begin{array}{l}\text { Yes, as planned } \\
\text { after } 1 \text { mo }\end{array}$ & $\begin{array}{l}\text { Postprocedure } \\
\text { oozing during } 4 \mathrm{~h}\end{array}$ \\
\hline 5 & PVI & 3 & SR & Dabigatran $^{\mathrm{a}}$ & 6 mo dabigatran ${ }^{a}$ & Yes, after 6 mo & No \\
\hline 6 & PVI & 4 & SR & No & 6 wk VKA (LMWH $\left.{ }^{b}\right)$ & Yes & No \\
\hline 7 & PVI & 5 & SR & No & 6 wk dabiagtran ${ }^{a}$ & Yes & No \\
\hline 8 & $\mathrm{PVI}$ & 6 & SR & No & 6 wk dabigatran ${ }^{a}$ & Yes & No \\
\hline
\end{tabular}

Abbreviations: AC, anticoagulation; ASA, $38 \mathrm{mg}$ acetylsalicylic acid; Hb, hemoglobin: $3.22 \mathrm{~g} / \mathrm{dL}=2.0 \mathrm{mmol} / \mathrm{L} ; 4.83 \mathrm{~g} / \mathrm{dL}=3.0 \mathrm{mmol} / \mathrm{L} ; \mathrm{pAF}$, paroxysmal atrial fibrillation; PVI, pulmonary vein isolation; SR, sinus rhythm; VKA, vitamin K antagonist: target INR 2.0-3.0.

a $110 \mathrm{mg}$ BID 4 weeks before PVI, last dose $24 \mathrm{~h}$ before intervention.

bTherapeutic LMWH until therapeutic INR.

Willebrand factor activity level of $0.66 \mathrm{IU} / \mathrm{mL}$, despite weightbased suppletion of 3,000 IU of Von Willebrand factor (Wilfactin; LFB, Les Ulis, France) half an hour before the blood collection. The FVIII level was at that moment $0.52 \mathrm{IU} / \mathrm{mL}$ ).

\section{After PVI}

Several hours (4-8 hours) after the procedure, therapeutic LMWH and VKA $(n=4)$ or dabigatran $(n=4)$ were started.

For anticoagulation management after PVI, see - Table 2. VKA anticoagulation was stopped in three out of four procedures after a mean of 4.7 weeks. Dabigatran was stopped in three out of four procedures after a mean use of 12.7 weeks. Patient 1 continued AC after both procedures because of a $\mathrm{CHA}_{2} \mathrm{DS}_{2}$-VASC 3 and factor level $>0.20 \mathrm{IU} / \mathrm{mL}$.
Four interventions were followed by intensive factor suppletion during 4 to 6 weeks (mean duration of 5 weeks) aiming and achieving trough FVIII levels of $>0.20 \mathrm{IU} / \mathrm{mL}$. The mean total clotting factor use was 76,625 IU (824 IU/kg) during this period.

\section{Success rates}

The success rate of a single PVI was 67\% (4/6); for two recurrent AFs, a second PVI ( 9 and 16 months after the first PVI) was performed (-Table 2).

Only two patients met the definition of long-term followup of over 36 months, with a 100\% success rate. However, the final overall success rate was five out of six: one patient had recurrent AF 42 months after the second PVI. 


\section{Complications}

Clinically relevant bleeding complications (grade 2 World Health Organization bleeding scale) occurred from the femoral vein puncture in two out of eight procedures ( - Table 2 ).

Patient 1 developed a small groin hematoma on the day of the procedure. He was agitated during the procedure and nonadherent to bedrest. His FVIII level was completely corrected for 36 hours. He was on therapeutic LMWH therapy before the procedure because of INR of $<2.0$ despite VKA. LMWH was stopped the evening after the procedure, because an adequate INR of 3.2 was obtained. He was discharged with a stable hematoma; hemoglobin level was not measured. Five days later he was readmitted in another hospital with a progressive groin hematoma and low hemoglobin $(-5.16 \mathrm{~g} /$ $\mathrm{dL}$ ) and a FVIII of $0.71 \mathrm{IU} / \mathrm{mL}$. His INR at admission was 2.4 . However, he had a good periprocedural FVIII recovery and trough levels and no inhibitor; it was assumed that his FVIII levels after discharge from, and at readmission at, the hospital must have been at least $0.35 \mathrm{IU} / \mathrm{mL}$. He was successfully treated with high-dose clotting factor concentrate for 1 day to stop bleeding. The hematoma completely resolved, and patient functionally fully recovered.

In patient 2 the procedure was complicated by an acute coughing spell. He reported a progressive discomfort and hematoma of his groin 3 days after the procedure with decreased hemoglobin. At that time his trough FVIII level was $0.31 \mathrm{IU} / \mathrm{mL}$ (the lowest during his hospital stay), the INR was 3.0, and he was still on therapeutic LMWH therapy. Because of the bleeding, FVIII was continued at higher dose aiming at trough levels of $>0.40 \mathrm{IU} / \mathrm{mL}$ and LMWH was stopped. He was discharged with 2 days delay. VKA was continued and FVIII was given (1,500 IU once-daily) aiming at trough levels $>0.40 \mathrm{IU} / \mathrm{mL}$ for 2 weeks. The patient fully recovered within these 2 weeks and thereafter the target through level was decreased to $0.20 \mathrm{IU} / \mathrm{mL}$.

Both patients with a severe groin bleed needed a redo PVI because of recurrent AF. Patient 1 was sedated during the second procedure and additional clotting factor correction was given on day 4 , to prevent late (re)bleeding. This time he was treated with dabigatran, a DOAC, instead of VKA. No bleeding occurred. The redo PVI in patient 2 was complicated by mild oozing from the puncture site for several hours while FVIII levels were corrected completely.

None of the patients developed thrombocytopenia or other bleeding tendency.

\section{Discussion}

In this small cohort study the success rate of PVI seems comparable with that of the general population. The success rate of a single PVI was $67 \%$ and after a second PVI $83 \%$ for achieving sinus rhythm. In the literature a success rate of up to $70 \%$ of patients with paroxysmal $\mathrm{AF}$, and around $50 \%$ in persistent $\mathrm{AF}$ is found, with most patients requiring more than one procedure. ${ }^{4}$

In the general population 5 to $7 \%$ of patients suffer from severe complications after PVI, of which 2 to $3 \%$ are lifethreatening, but usually manageable. The most severe com- plications are stroke $(<1 \%)$ and pericardial tamponade $(1-$ $2 \%) .{ }^{4}$ The incidence of clinical relevant groin hematoma after PVI in the general population is $0.9 \%{ }^{9}$ In our group it is likely that the combination of therapeutic LMWH, VKA therapy, decreased FVIII levels and mobilization shortly after the procedure have caused the high bleeding rate (25\%). In an observational study in the general population, bridging during ablation was associated with more bleeding complications, compared with continuing VKA. ${ }^{10}$ Bridging was also associated with an increased stroke risk. ${ }^{11}$ DOAC, however, is associated with a low incidence of stroke or transient ischemic attack and a significant reduction of major bleeding. ${ }^{12}$ In this small cohort we see the historical transition from bridging to nonbridging with a DOAC; in this small group no bleeding under DOAC was seen. We have chosen the DOAC dabigatran, a direct thrombin inhibitor, in a lower dose (110 $\mathrm{mg}$ twice daily) for patients with a bleeding disorder and an indication for anticoagulation. With this DOAC we have the option to reverse the anticoagulant if needed with idarucizumab. ${ }^{13}$ Furthermore, FVIII levels can be measured in case of emergency, in contrast to oral anti-Xa inhibitors that interfere with our laboratory assays.

Applying anticoagulation therapy in patients with bleeding disorders is complex.

$\mathrm{AF}$ has the risk of atrial thrombus embolization and ischemic stroke. The applicability of the $\mathrm{CHA}_{2} \mathrm{DS}_{2}$-VASC score ${ }^{4}$ in patients with clotting factor deficiency is questioned. ${ }^{5}$ There is lack of data on stroke and bleeding risk during anticoagulation in a population with increased bleeding tendency. As there are no prospective trials, a European working group (ADVANCE) gathered consensus for the management of $\mathrm{AF}$ in PWHs. ${ }^{5}$ Recently we reported an updated approach in anticoagulation management in $\mathrm{PWH}$ with $\mathrm{AF}^{14}$ We suggest to assess the bleeding risk based on clotting factor level and the thrombotic risk using the $\mathrm{CHA}_{2} \mathrm{DS}_{2}$-VASc score using adjusted cutoffs. A factor level of $0.20 \mathrm{IU} / \mathrm{mL}$ is thought to be safe for treatment with anticoagulation.

There is no data for the periprocedural management of coagulation for PVI.

Normally patients not on anticoagulation start 4 weeks before the PVI with anticoagulation. According to our protocol only patients with factor levels above $0.20 \mathrm{IU} / \mathrm{mL}$ were treated this way. Both patients did not report bleeding complications. On the other hand, patients not on anticoagulation did not have embolic events during this short time. For the future we are considering to withhold anticoagulation in patients with a low $\mathrm{CHA}_{2} \mathrm{DS}_{2}$-VASc score $(<4)$ with confirmation of absence of left atrium appendage thrombus by cardiac CT-scan before the procedure.

During PVI clotting factor suppletion is necessary to prevent a groin bleed and therefore anticoagulation is needed.

Following PVI, patients are treated with anticoagulation and in the case of FVIII levels $<0.20 \mathrm{IU} / \mathrm{mL}$, daily factor suppletion for at least 4 weeks. At this moment we think that withholding anticoagulation in patients with FVIII $<0.20 \mathrm{I} \mathrm{U} / \mathrm{mL}$ is not possible, because of an expected high risk of thrombus formation on the large coagulation area in the cardiac atria. 
In our cohort clinically relevant bleeding occurred 3 to 5 days after the procedure, a delay not uncommon in hemophilia as clot formation is impaired. Treatment consisted of stopping LMWH, which was already planned because of adequate INR, and increasing the FVIII target level for a limited time. We choose not to antagonize VKA, because postprocedural patients needed to be anticoagulated with VKA for a longer time.

\section{Conclusion}

Our results suggest that PVI is effective and a generally safe procedure in patients with bleeding disorders, provided that a strict control of hemostasis is attained and preferably a DOAC is used as anticoagulation. Because of the unexpected significant groin hematomas in two patients (on VKA with LMWH bridging) despite complete clotting factor correction for at least 24 hours, agitation during and the first hours after the procedure and early mobilization should be avoided. Furthermore, also in patients with bleeding disorders, DOAC seems safer compared with bridging of VKA with LMWH.

\section{Authors' Contributions}

P.R. van der Valk performed the research, analyzed the data, and wrote the manuscript. J.F. van der Heijden wrote part of the of the manuscript, concerning the cardiac intervention, performed and supervised the PVIs. E.P. Mauser-Bunschoten supervised the manuscript. R.E.G. Schutgens designed the research and edited the manuscript.

\section{Conflicts of Interest}

P.R. van der Valk received unrestricted research support from Baxter/Shire. J.F. van der Heijden: none. E.P. MauserBunschoten received unrestricted research/educational support from CSL Behring, Bayer, Baxter, LFB, Grifols, Novo Nordisk, Pfizer, Biotest, Roche, and Sanquin. R.E.G. Schutgens has received unrestricted research support from CSL Behring, Shire, Bayer, Novo Nordisk, and Sanquin.

\section{References}

1 Hassan S, Monahan RC, Mauser-Bunschoten EP, et al. Improved survival of patients with hemophilia in the Netherlands in the 21st century. Haemophilia 2019;25(Suppl 1):27-28
2 Darby SC, Kan SW, Spooner RJ, et al. Mortality rates, life expectancy, and causes of death in people with hemophilia A or B in the United Kingdom who were not infected with HIV. Blood 2007;110 (03):815-825

3 Plug I, Van Der Bom JG, Peters M, et al. Mortality and causes of death in patients with hemophilia, 1992-2001: a prospective cohort study. J Thromb Haemost 2006;4(03):510-516

4 Kirchhof P, Benussi S, Kotecha D, et al. 2016 ESC Guidelines for the management of atrial fibrillation developed in collaboration with EACTS. Europace 2016;18(11):1609-1678

5 Schutgens REG, Klamroth R, Pabinger I, Dolan G; ADVANCE working group. Management of atrial fibrillation in people with haemophilia-a consensus view by the ADVANCE Working Group. Haemophilia 2014;20(06):e417-e420

6 Schutgens REG, Klamroth R, Pabinger I, Malerba M, Dolan G; ADVANCE working group. Atrial fibrillation in patients with haemophilia: a cross-sectional evaluation in Europe. Haemophilia 2014;20(05):682-686

7 Teunissen C, Kassenberg W, van der Heijden JF, et al. Five-year efficacy of pulmonary vein antrum isolation as a primary ablation strategy for atrial fibrillation: a single-centre cohort study. Europace 2016;18(09):1335-1342

8 Tutuianu C, Szilagy J, Pap R, Sághy L. Very long-term results of atrial fibrillation ablation confirm that this therapy is really effective. J Atr Fibrillation 2015;8(02):1226

9 Potpara TS, Larsen TB, Deharo JC, et al; Scientific Initiatives Committee of European Heart Rhythm Association (EHRA). Oral anticoagulant therapy for stroke prevention in patients with atrial fibrillation undergoing ablation: results from the First European Snapshot Survey on Procedural Routines for Atrial Fibrillation Ablation (ESS-PRAFA). Europace 2015;17(06): 986-993

10 Wazni OM, Beheiry S, Fahmy T, et al. Atrial fibrillation ablation in patients with therapeutic international normalized ratio: comparison of strategies of anticoagulation management in the periprocedural period. Circulation 2007;116(22):2531-2534

11 Gopinath D, Lewis WR, Di Biase L, Natale A. Pulmonary vein antrum isolation for atrial fibrillation on therapeutic coumadin: special considerations. J Cardiovasc Electrophysiol 2011;22(02): 236-239

12 Cardoso R, Knijnik L, Bhonsale A, et al. An updated meta-analysis of novel oral anticoagulants versus vitamin $\mathrm{K}$ antagonists for uninterrupted anticoagulation in atrial fibrillation catheter ablation. Heart Rhythm 2018;15(01):107-115

13 Pollack CV Jr, Reilly PA, van Ryn J, et al. Idarucizumab for dabigatran reversal-full cohort analysis. N Engl J Med 2017; 377(05):431-441

14 Schutgens RE, van der Heijden JF, Mauser-Bunschoten EP, Mannucci PM. New concepts for anticoagulant therapy in persons with hemophilia. Blood 2016;128(20):2471-2474 